Int. J. Odontostomat.,

11(3):267-271, 2017.

\title{
Frequency of Oral Manifestation in Patients with Inflammatory Bowel Disease in Chile
}

\author{
Frecuencia de Manifestaciones Orales en Pacientes \\ con Enfermedad Inflamatoria Intestinal en Chile
}

Oviedo, C. ${ }^{1}$; Yañez, M. ${ }^{1}$ \& Pennacchiotti, V. ${ }^{2}$

OVIEDO, C.; YAÑEZ, M. \& PENNACCHIOTTI, V. Frequency of oral manifestation in patients with inflammatory bowel disease in Chile. Int. J. Odontostomat., 11(3):267-271, 2017.

SUMMARY: Inflammatory bowel disease (IBD) is an autoinflammatory chronic disorder of the gastrointestinal tract with a dysregulated immune response, being Crohn's Disease (CD) and Ulcerative Colitis (UC) the two main conditions. In literature the extra intestinal manifestations associated with IBD have been well documented. However, in our country, there are no studies about the oral manifestations. Having this information, is fundamental in order to optimize resources involved in diagnosis and treatment in a multidisciplinary level. Descriptive observational cross-sectional study, with a non-probabilistic sample for convenience with patients diagnosed with IBD belonging to the "CD-UC Group". In a period of four months the intraoral exam, diagnosis, and description of the lesions according location, type of illness, age, and sex were carried out. Thirty (30) patients (23 UC and 7 CD) filled the criteria of inclusion, $30 \%$ men and $70 \%$ women. 11 patients presented at least one oral lesion, being recurrent oral ulcer the most frequent, and two more specific lesions (macrocheilia and corrugated lesion). Of these patients, $37 \%$ presented at least one oral lesion, being the most frequent one recurrent oral ulcer (ROU). oral ulcer.

KEY WORDS: oral manifestations, inflammatory bowel disease, Crohn's disease, ulcerative colitis, recurrent

\section{INTRODUCTION}

Inflammatory bowel disease (IBD) is an auto inflammatory chronic disorder of the gastrointestinal tract with a dysregulated immune response, normally classified under two main conditions, Ulcerative Colitis (UC) and Crohn's Disease (CD) (Abraham \& Cho, 2009).

UC is a disease characterized by chronic inflammation of the intestinal mucosa, which usually affects the rectum and can also be extended to part, or the entirety of the colon. CD is a granulomatous transmural chronic inflammation which can affect any part of the digestive tube (from mouth to anus), and usually affects the terminal ileum and the proximal part of the colon (Boirivant \& Cossu, 2012).

The pathogenesis of IBD has not been clearly elucidated, but it is assumed that it is a multifactorial disease in which the immune system, genetics, microbiota, and environmental factors have a role in its aetiology (Fatahzadeh, 2009).

Along with the expected symptoms for a gastrointestinal affection, which are dependent of the extension and severity of the disease (diarrhea, rectal bleeding, urgency, mucus secretion, cramping, anorexia, fatigue, and overall discomfort) (Abraham \& Cho), patients with IBD can express an ample range of nonintestinal signs and symptoms, known as extra intestinal manifestations (EIM's), with a prevalence rate from $6 \%$ to $47 \%$, affecting organs like skin in organs like the skin, eyes, joints, and oral cavity (Lankarani et al., 2013).

Oral manifestations can have different presentations, which can occur because of reasons inherent to IBD as secondary to bad intestinal absorption or pharmacological treatment, as well as non-associated diseases (Fatahzadeh).

${ }^{1}$ Universidad del Desarrollo, Santiago, Chile.

${ }^{2}$ Oral Pathology and Medicine, Universidad de Chile, Santiago Chile. 
It has been determined that patients with IBD can show these oral manifestations years before IBD or even show up in presence of the active disease (Williams et al., 2008), therefore, the recognition of these patterns can help make a timely diagnosis of IBD at a multidisciplinary level (Fatahzadeh et al., 2009).

\section{MATERIAL AND METHOD}

An observational descriptive cross-sectional study was conducted in a population of the "CD-UC Group". The type of sample is non-probabilistic forconvenience and the size of the sample corresponds with the patients that fulfill the inclusion criteria $(n=30)$. One examiner was trained with a set of pictures photography for CD-UC lesions. The value for calibration for T. Kappa was between 0.61-0.8 (substantial agreement).

The inclusion criteria were: Patients between 18 and 80 years of age and being diagnosed with IBD. The exclusion criteria: Patients with a different associated systemic disease and women who were pregnant or nursing.

The sample was examined between April and June in 2016. A clinical record was used as an instrument to collect data, the systematized oral exam is the one recommended by the $\mathrm{NIH}$ for the detection of oral cancer and was carried out in the premises of the Clinic of the Universidad del Desarrollo, Chile.

Using the program for statistical data Microsoft Exce $^{\circledR} 2011$, descriptive statistics and contingency tables to analyze discrete variables were carried out.

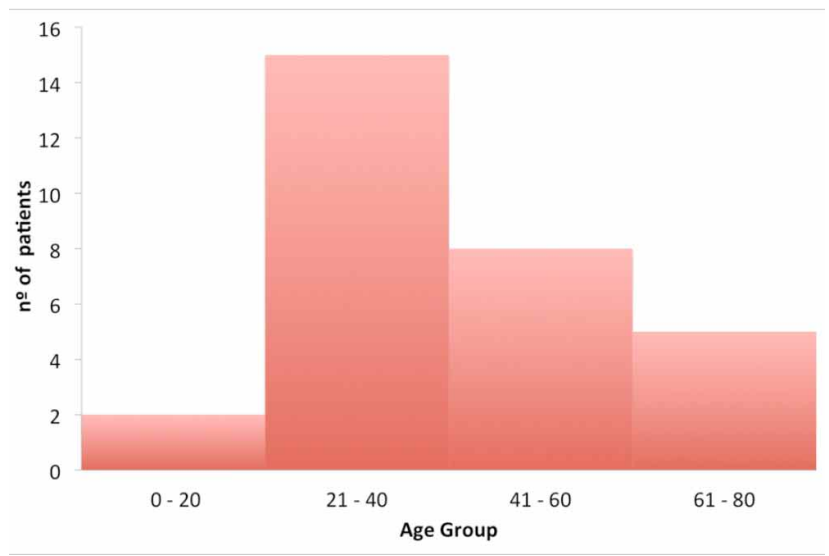

Fig. 1. Age distribution in IBD patients.
Before the exam, patients had to sign an informed consent approved by the Ethics Committee of the Faculty of Medicine-Clínica Alemana of the Universidad del Desarrollo. This Study meets the requirements set by the World Medical Association in the Declaration of Helsinki regarding ethical principles for medical research.

\section{RESULTS}

Thirty patients from the CD-UC Group participated in this study. The average age of the participants was 40 years of age. Most of the studied patients were between 21 and 40 years old, which is $50 \%$ of the sample, the other $50 \%$ were distributed as follows: 20 years old ( $6 \%$ ) between 41 and 60 years old (27\%) and older than 61 years old (17\%) (Fig. 1).

Of the studied patients, 23 have been diagnosed with UC and 7 with CD. In the group of patients diagnosed with UC, $30 \%$ are men and $70 \%$ are women. In the group diagnosed with CD, $29 \%$ are men and 71 $\%$ are women (Fig. 2).

Of the total number of examined patients, oral lesions were observed in 11 (37\%) patients, which are specified and described in Table I.

Of the patients, $3(10 \%)$ suffered from CD, as opposed to $8(27 \%)$ patients suffering from UC, showing oral lesions. The most common lesion in the sample was ROU (Fig. 3) and there were also two specific lesions suspected of EIM's in IBD; an indurated lesion of corrugated aspect in the oral mucosa (Fig. 4) and a macrocheilia or granulomatous cheilitis (Fig. 5).

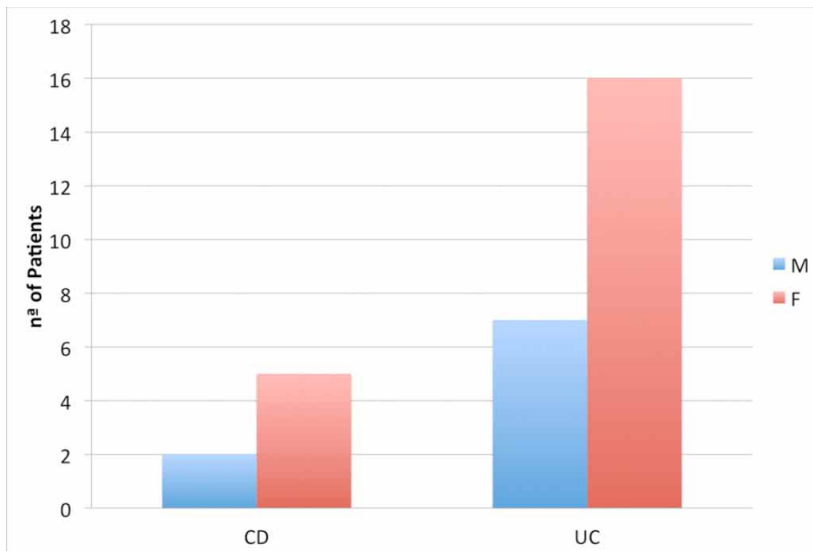

Fig. 2. Sex distribution in IBD patients. 


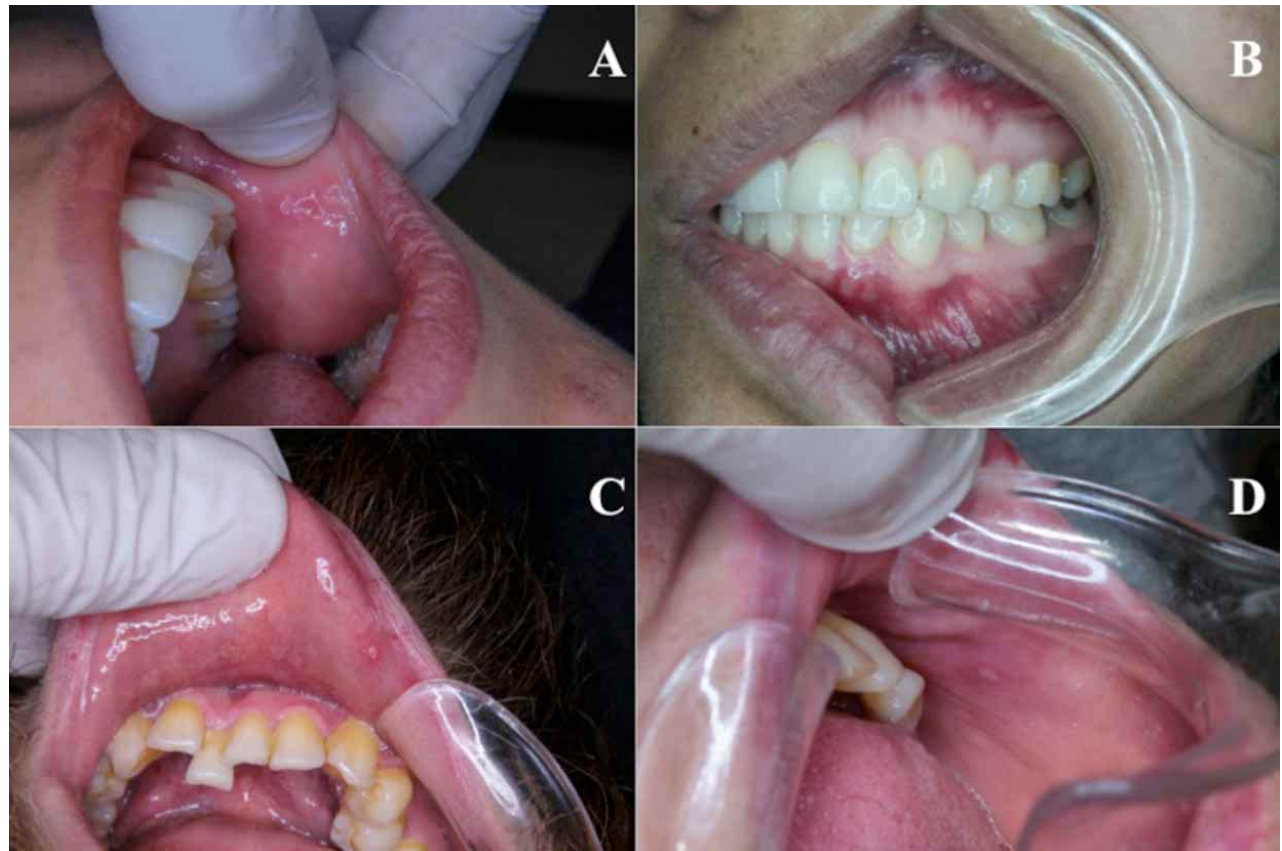

Fig. 3. Four Cases with ROU; A: UC Patient; B: CD Patient; C; UC Patient; D: UC Patient.

Table I. Description of oral lesions.

\begin{tabular}{lcccccc}
\hline Morphology & $\mathrm{L}$ & $\mathrm{G}$ & $\mathrm{BM}$ & $\mathrm{P}$ & $\mathrm{T}$ & Total \\
\hline $\begin{array}{l}\text { Hyperplastic Lesions } \\
\text {-Ridging }\end{array}$ & - & - & 1 & - & - & 1 \\
Ulcerative Lesions & & & & & & \\
-Aphtae & 1 & 1 & 2 & - & - & 4 \\
-Ulcer & - & - & & 1 & - & 1 \\
-Angular ulcer & 1 & - & - & - & - & 1 \\
-Scar & - & - & - & - & 1 & 1 \\
$\begin{array}{l}\text { Other Lesions } \\
\text {-Edema }\end{array}$ & 1 & - & - & - & - & 1 \\
-Erythema & - & 1 & - & - & 1 & 2 \\
Total & 3 & 2 & 3 & 1 & 2 & 11 \\
\hline
\end{tabular}

Of the 11 patients with oral manifestations, 9 are women, $43 \%$ of all the female patients examined and 2 of them are men, $22 \%$ of all male patients examined.

In relation to the age range, regarding the studied patients with oral manifestations ( $37 \%$ ), $16.5 \%$ are in the age group between 21 and 40 years of age, $10.5 \%$ are in the group between 41 and 60 , and $10 \%$ are between 61 and 80 years of age.

L, lips; G, gingiva; BM,buccal mucosa; P, palate; T, tongue.

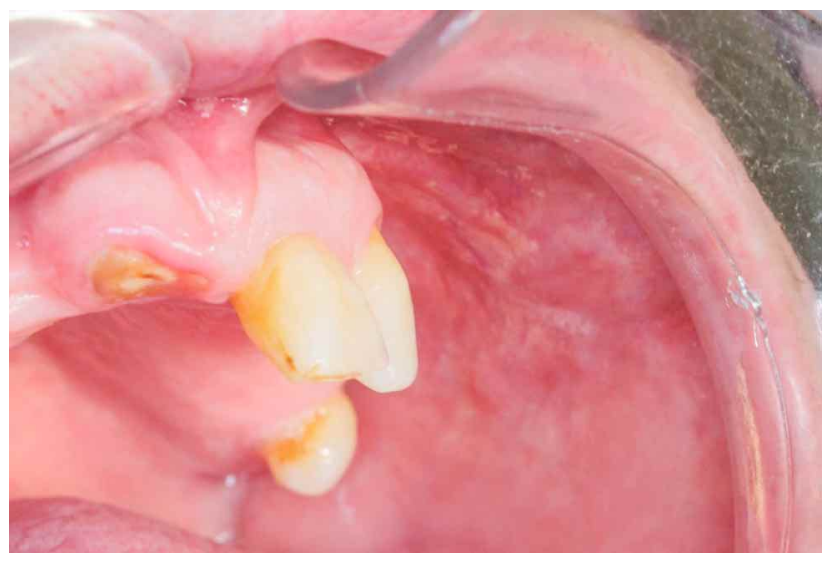

Fig. 4. UC Patient-Corrugated lesion.

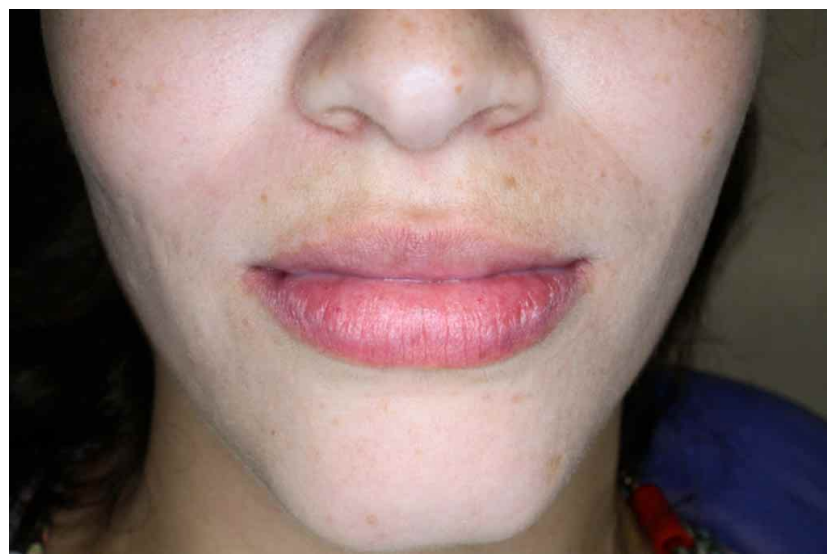

Fig. 5. CD Patient-Macrocheilia. 


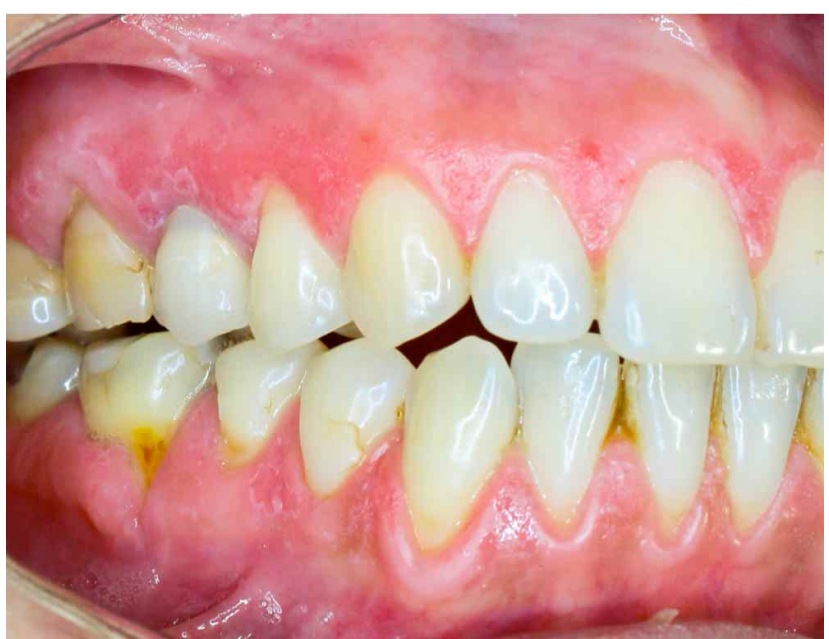

Fig. 6. CD Patient-Chronic Desquamative gingivitis.

\section{DISCUSSION}

From the total of patients belonging to the group, 30 patients were examined, of which $37 \%$ presented some type of oral lesion. Lisciandrano et al. (1996) in France estimated the prevalence of oral lesions in 198 patients diagnosed with IBD (77 with CD and 121 with UC), determining a rate of $20 \%$. Pittock et al. (2001) in Ireland reported a frequency of $48 \%$ for a pediatric population, however, it must be considered that the sample of the studied group was of 25 patients with recently diagnosed $C D$, without pharmacological treatment. On the other hand, a study carried out in Iran by Elahi et al. (2012), examined 50 adult patients with UC reporting a $20 \%$ rate of oral lesions of which were only oral ulcers.

The limitations of the study to carry out an exploration of a larger sample were: patients who did not fit the criteria, patients who did not give informed consent, patients who were not able to attend because of schedule issues, and aggravation of the disease making it impossible to go to the premises of the Clinic where the study was being carried out.

The sample of this study deals with adults with previous pharmacological treatment, which was also used for the treatment of EIM's (Rothfuss et al., 2006), nevertheless, the frequency of oral lesions coincides with the range of prevalence estimated by most publications described in the review of Lankarani et al. (between 20 and $50 \%$ ) revealing a wide variety in the frequency rate, mainly due to the variation in the age range and sample size, race, genetic background, pharmacological treatment, activity status of the disease, the operator or examiner's experience in diagnosis, and the variation in the definition of the lesions.

The most frequent lesion found on the sample was ROU, similar result found in the published literature (Plauth et al., 1991; Pittock et al.; Scheper \& Brand, 2002; Williams et al.; Lourenço et al., 2010; Elahi et al.; Laranjeira et al., 2015). Even though the literature indicates the relation between these lesions with activation or flare-up of the intestinal pathology (Fatahzadeh), we need to consider also that these lesions are equally frequent in healthy patients $(20 \%$ of the population). In patients with IBD there is a tendency of constant recurrence over time. The relation between these lesions and the disease can be linked with the medication for the treatment such as sulfasalazine, correlated with the concentration of sulfapyridine in saliva together with the one in plasma, just as the 5aminosalicylate excretion in saliva, could cause ROU in some patients (Scheper \& Brand). Furthermore, the literature associates it with nutritional deficiencies resulting from the insufficient supply of vitamin $B$, albumin, iron, folic acid, zinc, niacin, and other elements (Boh \& al-Smadi, 2002). These nutritional deficiencies can be the result of intestinal affectation as well as the medication used for the treatment of IBD.

The suspicion specific lesions found in the study are the macrocheilia of the inferior lip in a patient with $C D$ (Fig. 5), being this one of the most frequent lesions in CD (Lankarani et al.). The diagnosis of granulomatous cheilitis, it necessarily requires of a histopathological examination which was not done because of delimitations of the protocol limited to the clinical examination of the mucosa. The second lesion detected was a corrugated lesion in the oral mucosa in a patient with UC (Fig. 4), being this type of lesion a pathognomonic sign observed in $C D$, which has no direct relation with the activity of the disease of the patient at issue (UC). It is worth mentioning that the definitive diagnosis must be confirmed by the histopathological analysis (Fatahzadeh).

Finally, a lesion reactive and/or associated to CD was documented, with a possible diagnosis of chronic desquamative gingivitis (Fig. 6). In 198914 cases of lichen planus associated to UC (Dhawan \& Fields, 1989) were documented. On the contrary, there have not been any publications describing these types of lesions as $C D$, however, there are publications describing lesions of lichenoid aspect in relation to sulphonamides with immunomodulatory effect like sulfasalazine (Katz et al., 2003). 
The sample of the study indicates that most of the examined patients suffer from UC, with a predilection for the female sex and belonging to the age range between 21 and 40 years of age, data that coincides with the largest concentration of oral lesions. However, due to the small size of the sample, this is not data significant enough to make any kind of association with the characteristics of the patients or any comparison with the data in international literature.

\section{CONCLUSIONS}

1. $37 \%$ of the studied patients presented at least one lesion or oral manifestation.

2. The most frequent oral manifestation was the ROU. 3. Patients of the female sex, with UC and in the age range between 21 and 40 years of age present oral lesions with higher frequency.

4. The frequency of oral lesions in the sample coincides with the frequency range of EIM's published in the literature.

5. It is suggested that further research should be done and in a larger scale to know with precision the prevalence of these lesions in patients with IBD in our country.

OVIEDO, C.; YAÑEZ, M. \& PENNACCHIOTTI, V. Frecuencia de manifestaciones orales en pacientes con enfermedad inflamatoria intestinal en Chile. Int .J. Odontostomat., 11(2):267$271,2017$.

RESUMEN: La Enfermedad Inflamatoria Intestinal (EII) es un desorden inmunitario autoinflamatorio crónico del tracto gastrointestinal, siendo la Enfermedad de Crohn (EC) y la Colitis Ulcerativa (CU) sus dos condiciones principales. Se ha documentado en la literatura acerca de las manifestaciones extraintestinales asociadas a Ell. Sin embargo, en nuestro país, no existen estudios acerca de las manifestaciones orales. Contar con esta información es fundamental para optimizar los recursos involucrados en el diagnóstico y tratamiento a nivel multidisciplinario. Se realizó un estudio observacional descriptivo de corte transversal, con un muestreo no probabilístico por conveniencia con pacientes diagnosticados de Ell pertenecientes a la "Agrupación EC-CU". En un periodo de 4 meses se realizó el examen intraoral, diagnóstico y descripción de lesiones según localización, tipo de enfermedad, edad y sexo. Resultados: 30 pacientes (23 CU y 7 EC) cumplieron con los criterios de inclusión, $30 \%$ hombres y $70 \%$ mujeres. De los sujetos, 11 pacientes presentaron al menos una lesión oral, la úlcera recurrente oral fue la lesión más frecuente y se encontraron dos lesiones específicas (macroqueilia y lesión de aspecto corrugado). Un $37 \%$ de los pacientes presentaron al menos una lesión oral, en donde la lesión más frecuente fue la úlcera recurrente oral.
PALABRAS CLAVE: manifestaciones orales, enfermedad inflamatoria intestinal, enfermedad de crohn, colitis ulcerativa, úlcera recurrente oral.

\section{REFERENCES}

Abraham, C. \& Cho, J. H. Inflammatory bowel disease. N. Engl. J. Med., 361(21):2006-78, 2009.

Boh, E. E. \& al-Smadi, R. M. Cutaneous manifestations of gastrointestinal diseases. Dermatol. Clin., 20(3):533-46, 2002.

Boirivant, M. \& Cossu, A. Inflammatory bowel disease. Oral Dis., 18(1):1$15,2012$.

Dhawan, S. S. \& Fields, K. Lichen planus and ulcerative colitis--is there a relationship? Int. J. Dermatol., 28(8):534, 1989.

Elahi, M.; Telkabadi, M.; Samadi, V. \& Vakili, H. Association of oral manifestations with ulcerative colitis. Gastroenterol. Hepatol. Bed Bench, 5(3):155-60, 2012.

Fatahzadeh, M. Inflammatory bowel disease. Oral Surg. Oral Med. Oral Pathol. Oral Radiol. Endod., 108(5):e1-10, 2009.

Fatahzadeh, M.; Schwartz, R. A.; Kapila, R. \& Rochford, C. Orofacial Crohn's disease: an oral enigma. Acta Dermatovenerol. Croat., 17(4):289-300, 2009

Katz, J.; Shenkman, A.; Stavropoulos, F. \& Melzer, E. Oral signs and symptoms in relation to disease activity and site of involvement in patients with inflammatory bowel disease. Oral Dis., 9(1):34-40, 2003.

Lankarani, K. B.; Sivandzadeh, G. R. \& Hassanpour, S. Oral manifestation in inflammatory bowel disease: a review. World $J$. Gastroenterol., 19(46):8571-9, 2013.

Laranjeira, N.; Fonseca, J.; Meira, T.; Freitas, J.; Valido, S. \& Leitão, J. Oral mucosa lesions and oral symptoms in inflammatory bowel disease patients. Arq. Gastroenterol., 52(2):105-10, 2015.

Lisciandrano, D.; Ranzi, T.; Carrassi, A.; Sandella, A.; Campanini, M. C.; Velio, P. \& Bianchi, P. A. Prevalence of oral lesions in inflammatory bowel disease. Am. J. Gastroenterol., 91(1):7-10, 1996.

Lourenço, S. V.; Hussein, T. P.; Bologna, S. B.; Sipahi, A. M. \& Nico, M. $M$. Oral manifestations of inflammatory bowel disease: a review based on the observation of six cases. J. Eur. Acad. Dermatol. Venereol., 24(2):204-7, 2010.

Pittock, S.; Drumm, B.; Fleming, P.; McDermott, M.; Imrie, C.; Flint, S.; Bourke, B. The oral cavity in Crohn's disease. J. Pediatr., 138(5):76771, 2001.

Plauth, M.; Jenss, H. \& Meyle, J. Oral manifestations of Crohn's disease. An analysis of 79 cases. J. Clin. Gastroenterol., 13(1):29-37, 1991.

Rothfuss, K. S.; Stange, E. F. \& Herrlinger, K. R. Extraintestinal manifestations and complications in inflammatory bowel diseases. World J. Gastroenterol., 12(30):4819-31, 2006.

Scheper, H. J. \& Brand, H. S. Oral aspects of Crohn's disease. Int. Dent. J., 52(3):163-72, 2002.

Williams, H.; Walker, D. \& Orchard, T. R. Extraintestinal manifestations of inflammatory bowel disease. Curr. Gastroenterol. Rep., 10(6):597605, 2008.

Corresponding author:

Sebastian Oviedo

Universidad del Desarrollo

Santiago

CHILE

Received: 04-04-2017

Accepted: 07-07-2017

E-mail: sebaoviedoc@gmail.com 